for ionizing the oxygen atoms is more than a hundred times greater than the energy available for ionizing $\mathrm{O}_{2}$ and $\mathrm{N}_{2}$. This fits in with the point of view developed above that the energy of the part of the solar spectrum producing the $F_{2}$-ionization is in excess when passing through the layer.

\section{LETV HARANG.}

Auroral Observatory,

Tromsø.

Jan. 1.

${ }^{1}$ Appleton and Naismith, Proc. Roy. Soc., A, 150, 635 (1935). Schafer and Goodall, Proc. Inst. Rad. Eng., 23, 670 (1934). Kirby, Berkner and Stuart, Bur. Stand. $J$. Res., 12, 15 (1934). Harang, Gerl. Beitr. Geophysik, 46, 438 (1936).

"NATURE, 136, 52 (1035).

${ }^{3}$ Harang, Terr. Mag., 41, 143 (1936).

- Proc. Roy. Soc., A, 131, 353 (1931).

${ }^{5}$ loc. eit.

\section{Excitation of Raman Spectra with the aid of 'Optical Catalysers'}

Prosad and Bhattacharya have reported ${ }^{1}$ the 'optical catalysis' of the Raman effect. That this phenomenon should exist is in accordance with the theory of the Raman effect along classical lines which we have presented elsewhere ${ }^{2}$. Moreover, it is possible from that theory to predict the circumstances in which the catalysis should be most pronounced.

According to this theory, the emission of the Raman lines is facilitated by the close proximity of a system resonant at the frequency of the difference line or anti-resonant at that of the sum line. It is hindered by the reverse of these conditions. If the observed effect is due to such a resonance in the 'catalyser', we should expect the following experimental results : (1) The effectiveness of a particular 'catalyser' should vary with the frequency of the incident light, being a maximum for some one frequency. (2) Two substances having different infra-red frequencies should be 'catalysed' by the same added substance, provided the incident frequencies are so adjusted as to make the difference, or sum, frequencies the same for both. (3) It should be possible to find substances the addition of which reduces the Raman effect. In particular, if the effect of a 'catalyser' is found to show a maximum for a particular incident frequency, a shift of the incident frequency, such that the new sum frequency coincides with the old difference, should reduce the effect below normal.

The above considerations apply particularly to experiments at low temperatures, and the effects described might easily be masked at higher temperatures.

Bell Telephone Laboratories,

$$
\text { R. V. L. HaRtrley. }
$$

New York.

Jan. 11.

${ }^{1}$ NATURE, 138, 510 (Sept. 19, 1936).

'Bell System Tech. J., 424 (July 1936).

\section{Fluorescence of the Bivalent Rare Earths}

IN a letter in NATURE of January 19, 1935', I stated that the blue fluorescence shown by fluorites is due to bivalent europium produced through reduction of traces of trivalent europium by radium rays. In the same way a yellow-green band shown by some fluorites at low temperatures can be ascribed to bivalent ytterbium. Later ${ }^{2}$, it was shown that a red fluorescence band that had puzzled us a good deal is due to bivalent samarium.
From the investigations of $G$. Jantsch and $W$. $K^{\prime} \mathrm{Hmm}^{3}$, it appears that these three rare earths, europium, ytterbium and samarium, are the only ones that can be obtained definitely as bivalent ions; whilst for thulium there are at least distinct indications of the formation of traces of bivalent compounds, for the other rare earths there are scarcely any. Taking the hypothetical connexion between the formation of bivalent ions and the appearance of radiophoto-fluorescence bands as a guiding hypothesis, one might hope to get such a fluorescence also with suitable substances containing traces of thulium.

Through the courtesy of Dr. P. Hoernes, I got from the Degea (Auergesellschaft) in Berlin a sample said to contain 93 per cent $\mathrm{Tu}_{2} \mathrm{O}_{3}, 3$ per cent $\mathrm{Yb}_{2} \mathrm{O}_{3}$ and 4 per cent $\mathrm{Cp}_{2} \mathrm{O}_{3}$, for which my best thanks are due. A small amount of this substance was added to calcium sulphate (concentration $10^{-3}$ ). After exposure to radium rays, the preparation was tested with filtered ultra-violet light. At room temperature, nothing was observed, but on lowering the temperature a red fluorescence appeared that became very brilliant at the temperature of liquid air. Calcium sulphate preparations with $10^{-3}$ erbium or $10^{-3}$ ytterbium, the neighbouring elements, showed under the same conditions a much weaker fluorescence, evidently due to inevitable traces of thulium. The maximum of the thulium band has nearly the same wave. length as that of samarium in calcium sulphate, about $620 \mathrm{~m} \mu$, but it is-at the same temperaturedistinctly narrower and reacts quite differently towards changes of temperature, increasing in bright ness with decreasing temperature, whilst the samarium band gradually disappears on nearing liquid air temperature. At the latter, the thulium band shows a structure which needs further investigation.

I have to thank Miss E. Rona for preparing the synthetic material, and Miss B. Karlik for photographing the spectra. A detailed report will be presented to the Vienna Academy of Sciences.

Institut für Radiumforschung,

K. Przibram.

Jan. 20.

${ }^{1}$ See also Wien Ber., IIa, 144, 141 (1935) ; Z. Phys., 102, 331 (1936).

2 Wien. Anzeiger, Dec. 3, 1936.

${ }^{3}$ Jantsch, G., and Klemm, W., Z. anorgan. Chem., 216, 80 (1933).

\section{Claims of Geology in School Courses of General Science}

Prof. Trueman's letter in Nature of February 6, as to the parlous state of geology in relation to teaching in schools, leads one to inquire further into the causes of this state of things.

Considering first the cultural aspect of the question, it is abundantly clear that the purely cultural value of geology is insufficiently realized by teachers in secondary schools. This is all the more puzzling in view of the rapid hold which it exercises on the imagination when properly taught, and the extreme value of its field side to adolescents.

My experience during the last twenty years has led to the conclusion that geologists lost a valuable chance of introducing their subject into schools when they allowed geographers to seize a branch (physical geology) in the great expansion which took place in geographical studies just after the Great War.

Turning to the utilitarian side of the problem, it is found that apart from mining and oil geology, 